\title{
EVALUATION OF POISSON'S RATIO RANGE FOR FRACTURE PRESSURE GRADIENT (FPG) PREDICTION FOR NIGER DELTA FORMATION
}

\author{
D. E. Imhanzuaria ${ }^{1, *}$ and K. O. Bello ${ }^{2}$ \\ 1,2, Department of Petroleum Engineering, University of Benin, Benin City, Edo State, Nigeria. \\ Email addresses: ${ }^{1}$ imhanzuariadarlington@gmail.com, ${ }^{2}$ belloko@uniben.edu
}

\begin{abstract}
The knowledge of Fracture Pressure Gradient (FPG) from Pore pressure and Overburden pressure prediction is one of the requirements to safe drilling. This provides sufficient information to drilling engineers on the appropriate drilling mud weight, casing design criteria, and optimum penetration rates. Several models were evaluated for formation fracture pressure gradient (FPG) prediction and were found to be inaccurate for the Niger Delta environment. A modified Eaton model has been developed for the Niger Delta environment that considers the variation of the Poisson's ratio (v) with depth. It was also established from the sensitivity analysis carried out that the density input parameter is critical in the development of the modified model. The results showed that the formations will tend to fracture at depths of about 6700ft-10000ft in the Niger Delta area at Poisson's ratio of about 0.35-0.40. In the light of the foregoing, the modified model was found to be most accurate for predicting formation fracture pressure gradient (FPG) particularly for the Niger Delta environment.
\end{abstract}

Keywords: FPG Models, Fracture Pressure Gradients, Poisson Ratio, Niger Delta, Sensitivity Analysis.

\section{INTRODUCTION}

The cost from Non Productive Time (NPT) resulting from rig down time when accrued proves to be highly prohibitive, hence the knowledge of Fracture Gradient from Pore pressure and Overburden pressure prediction is one of the requirements to safe drilling which then gives the drilling engineers confident on the right drilling mud weight to use, casing design, reliable penetration rates, and provides proper logistics for the drilling operation.

Fracture Pressure Gradient (FPG) is the pressure required to induce fractures in the rock formation at a given depth [1]. However, according to [2], Poisson ratio $(v)$ is a rock property that describes the behavior of rock stresses in one direction of the least principal stress when pressure is applied in another direction. In most cases the maximum vertical principal stress due to the overlying rock and interstitial fluid pressure is the Overburden Pressure [3]. In the context of fracture gradient, only the rock tensile strength is of importance [1], thus a formation will fracture when the pressure in the wellbore is equal to or greater than the minimum (least) principal stress (assuming the rock tensile strength is negligible). The fracture will propagatealong the path of least resistance which is perpendicular to the direction of the minimum principal stress [2]. Thus, fractures will be vertical in areas (sufficiently and relatively deeper depths) where the minimum principal stress is horizontal as shown in Figure 1a; and fractures will be horizontal in areas (shallow areas or close to surface) where the minimum principal stress is vertical as shown in Figure $1 b$ [4].

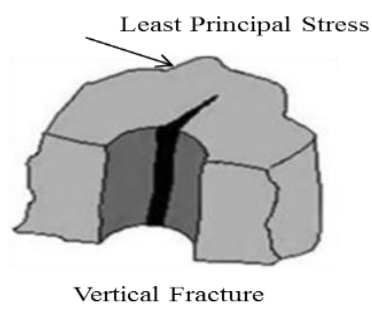

Figure 1a: Vertical Fracture

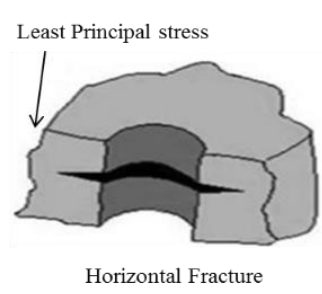

Figure 1b: Horizontal Fracture 


\subsection{Geologic Setting of Niger Delta}

The Niger Delta is located in the Gulf of Guinea, Central West Africa at the culmination of the Benue Trough and is considered one of the most prolific hydrocarbon provinces in the world [5]. It is a thick accumulation of tertiary deltaic sediments bordering the Atlantic Ocean and extends from longitude $3^{\circ} \mathrm{E}-$ $9^{\circ} \mathrm{E}$ and latitude $4^{\circ} 30^{\prime} \mathrm{N}-5^{\circ} 20^{\prime} \mathrm{N}$ [6]. The proto delta developed in the Northern part of the basin during the Campanian transgression and ended with the Paleocene transgression [7]. The modern delta started forming during the Eocene period to recent.

The lithostratigraphy of the Tertiary Niger Delta can be divided into three major units; Akata, Agbada, and Benin formations with depositional environments ranging from marine, transitional and continental settings respectively. Their ages range from Eocene to Recent, but they transgress time boundaries [8]. This region due to its hydrocarbon proliferation, then has 'depo-belts'; depositional belts or "depo belts" consists of a series of off-lapping siliciclastic sedimentation cycles or mega-sedimentary belts. Evammy, et al [9] referred to this structure as mega structure while [10] were the first to call them depo-belts.

There are seven regional depo-belts which are discerned along the north-south axis of the Niger Delta, each with its own sedimentation, deformation and petroleum history[8], and the activity in each depo-belts has progressed in time and space toward the south-south west through stepwise alluvial progradation facilitated by large scale withdrawal and forward movement of the underlying shale. These depo-belts include; the Northern Delta, the Greater Ughelli, the Central Swamp I\&II, the Coastal Swamp I\&II, and the Offshore depo-belts [8].

Due to the fact that the Niger Delta region is a hydrocarbon proliferation area, hence it is pertinent that before the exploration and production of petroleum, a proper and accurate prediction of fracture gradient is essential in order to ensure safe drilling operation whilst ensuring an effective well planning, good casing design and casing depth selection.

Although, a number of correlations have been developed to enable for prediction of formation fracture pressure gradient (FPG), many of which were developed for the Gulf of Mexico region (GOM) [1]. These models include; the Hubbert and Willis method [11], the Mathews and Kelly method [12], the Pennebaker method [13], the Eaton's method [14], the Christman method [15]. The Eaton's model [14] happens to be the most widely used method of predicting formation fracture pressure gradient (FPG) in the petroleum industry because it considers Poisson's ratio $(v)$ with depth which can be said of that it is characteristic of the Niger Delta area [1]. Hence, in this study, the Eaton's model [14]is been utilized due to its wide applications for predicting formation fracture pressure gradient (FPG) in the petroleum industry, and then this model was modified in order to suit the Niger Delta area while also carrying out a sensitivity analysis on the model.

\section{MATERIALS AND METHODS}

This study was carried out using six (6) well data from the Niger Delta region, the data used was well logs in American Standard Code for Information Interchange (ASCII) format. Because of the existing laws within the Oil companies in Nigeria, the exact location of the wells cannot be disclosed.

The well logs data used included Gamma-Ray (GR); PSonic (DTC); Resistivity; Density logs; however, some of the wells lack complete set of data, as such, transposition/ or transformation of the other logs were done to get the necessary log data to be used as described by some existing models in literature.

The Microsoft Office Excel 2010 was deployed for data analysis: for log conditioning such as using the "IF COMMAND" statement to suit some parameters as required; for crossplots of some well logs parameter such as Shale resistivity vs Depth in order to obtain the Shale Normal Compaction Trend Line (SNCTL) and ratios of Observed to Normal shale resistivity; estimation of shale volume $V_{\text {sh }}$ from the cross plot of GR log vs Depth; estimation of Poisson ratio $v_{\text {, }}$ Overburden pressure gradient (GoB), and Pore pressure gradients (Gpp), and estimation of the formation of fracture pressure gradient (FPG).

The key processing sequences of operation carried out in the study includes:

$>$ Acquisition, identification, and review of obtained well logs data.

> Estimation of the Overburden Pressure Gradient (GoB).

> Estimate the Pore pressure Gradient (Gpp) while utilizing the Eaton's method.

> Estimate the Poisson ratio utilizing the obtained sonic well logs data and log conditioning the Poisson ratio values.

$>$ Estimate the Fracture Pressure Gradient (FPG) utilizing the modified Eaton's method.

$>$ Carry out a sensitivity analysis on each of the wells for a particular predicted fractured depth, and then determine how the input well log data 
affects the modified Eaton's formation fracture pressure gradient (FPG) respectively.

\subsection{Lithology Discrimination\& Volumeof Shale Estimation}

Gamma Ray (GR) log was used to discriminate between sand and shale lithology. The shale volume fraction was generated using the Microsoft Office Excel 2010 and the standard equation is;

$$
V_{\text {sh }}=\frac{G R_{\log }-G R_{\min }}{G R_{\max }-G R_{\min }}
$$

where; $\mathrm{GR}_{\mathrm{log}}=$ the log response, $\mathrm{GR}$ min $=$ the minimum log value, and is said to be the log value in clean sand, $\mathrm{GR}_{\max }=$ the maximum log value, and is said to be the log value in clean shale.

In order to obtain the shale cut-off point, since literature suggested thatthe shale volume is subjective, a 0.2 (based on the distribution of the shale volumes, $V_{\text {sh, }}$ you judiciously select a shale cut off point) value was used as shale cut off point which enabled log conditioning.

\subsection{Overburden Pressure Gradient Estimation}

(Gов)

This is an important parameter in both pore pressure and fracture pressure gradients estimations. The overburden pressure gradient (GoB) was generated from the bulk density obtained from the well log. The simple equation used for this was;

$\mathrm{GoB}=\rho_{\mathrm{b}} * 0.433(\mathrm{psi} / \mathrm{ft})$

where $\mathrm{G}_{\mathrm{OB}}=$ overburden pressure gradient (psi/ft), $\rho_{b}=$ bulk density $(\mathrm{g} / \mathrm{cc}), 0.433=$ conversion factor

\subsection{Pore Pressure Gradient (Gpp) Estimation}

This is one of the most dependent variables [16]. The method utilized was the Eaton's model which uses resistivity ratios as the qualifier [17]. The Eaton's technique requires an accurate overburden pressure gradient (Goв) calculation, GR log which identifies shales zones, and resistivity logs [17].The Eaton's method for pore pressure gradient (Gpp) estimation equation is;

$$
G_{P P}=G_{O B}-\left(G_{O B}-0.433\right) \times\left(\frac{R_{O}}{R_{n}}\right)^{1.2}
$$

where; Gpp = Pore Pressure Gradient (psi/ft), $\mathrm{G}_{\mathrm{oB}}=$ Overburden Pressure Gradient (psi/ft), $\quad \mathrm{Ro}=$ Observed Shale resistivity $(\mathrm{ohm}-\mathrm{m}), \mathrm{Rn}=$ Normal Shale Resistivity (ohm-m).

\subsection{Shale Normal Compaction Trend Line (SNCTL)}

Once the cross plots of Observed Shale Resistivity Ro vs Depth is made, a normal compaction shale resistivity trend line is constructed. This trend line is often a "best fit" line through the observed shale resistivity log values [17].Then the ratio of the observed to normal shale resistivity $\left(R_{0} / R_{n}\right)$ when powered to a value of 1.2 is inputted into the Eaton's method of Pore Pressure Gradient (Gpp) estimation as shown in equation 3.

\subsection{Poisson Ratio Estimation}

Poisson ratio is an elastic constant of a rock and thus a rock property itself. Accordingly, Poisson ratio $v$ is formally defined as the ratio of the lateral strain to the longitudinal strain in a body that has been stressed longitudinally within its elastic limit [17].

The Poisson ratio $(v)$ can be estimated once the primary $V_{p}$ and secondary $V_{s}$ waves velocity are known once it has been derived from the compressional and/or shear (DTC and/or DTS) sonic logs respectively using this equation;

$$
v=\frac{\mathrm{Vp}^{2}-2 \mathrm{Vs}^{2}}{2\left(\mathrm{Vp}^{2}-\mathrm{Vs}^{2}\right)}
$$

where; $v=$ Poisson ratio (dimensionless), $V_{p}=$ Primary wave velocity $(\mathrm{m} / \mathrm{s}), V_{s}=$ Secondary wave velocity $(\mathrm{m} / \mathrm{s})$.

\subsection{Fracture Pressure Gradient (FPG) Prediction} The model implored was the most accurately and widely used Eaton's fracture pressure gradient (FPG) prediction model which was modified. It is a more adaptable method because it takes into account variable overburden pressure gradient (Gов) and Poisson ratio $v$.

A low pore pressure in a zone that has a higher Poisson ratio may have a higher calculated fracture pressure gradient (FPG) than another zone that has a higher pore pressure and lower Poisson's ratio [17].

The Fracture Pressure Gradient (FPG) prediction model by Eaton [14] is presented as;

$$
F P G=\left(\frac{v}{1-v}\right) \times\left(G_{O B}-G_{P P}\right)+G_{P P}
$$

where; $F P G=$ Formation Pressure Gradient (psi/ft), $v=$ Poisson ratio (dimensionless), $\mathrm{G}_{\mathrm{B}}=$ Overburden Pressure Gradient (psi/ft), Gpp= Pore Pressure Gradient (psi/ft).

However, the modified Eaton method used is presented as;

$$
F P G=\left(\frac{0.486\left(V_{p}-7566\right) \times\left(747-V_{p}\right)}{V_{p}^{2}}\right)
$$

Where $V_{p}=$ primary wave velocity $(\mathrm{m} / \mathrm{s})$, and the rest variables are same as stated in equation 5 . 
Subsequently, a cross plot of formation fluid pressure gradient and fracture pressure gradient (FPG) both against depth is made; an analysis is then carried out on this plot, then depths where a visible crossover of both gradients is noticed is assumed to fracture, as such fracture pressure gradient (FPG) is important mostly for selecting the depths for casing seats.

\section{RESULTS AND ANALYSIS}

The Microsoft Office Excel 2010 was largely used for data analysisin order to obtain crossplots of the six (6) well logs parameter (i.e. parameters as depth, density, Resistivity, \& DTC) such as Shale resistivity vs Depth, the Shale Normal Compaction Trend Line (SNCTL) and ratios of Observed to Normal shale resistivity were estimated. These are estimation of shale volume $V_{s h}$ from the cross plot of GR log vs Depth, estimation of Poisson ratio $v$, Overburden pressure gradient (GoB), and Pore pressure gradients (Gpp) e.t.c.

At a first glance, the various indirect fracture pressure gradients (FPG) models looks different; however,[18]compared them and found that they were very similar in that there is a constant attached known as the Correlation Coefficient, while still having the Overburden pressure gradient $\mathrm{G}_{\mathrm{B}}$, and the Formation pore pressure gradient Gpp respectively; hence the general equation for these models is;

$F P G=K\left(G_{O B}-G_{p P}\right)+G_{p P}$

where; $F P G=$ Formation fracture pressure gradient (psi/ft), K= constant (correlation coefficient), GoB\& $\mathrm{Gpp}=$ Overburden \& Formation pore pressures gradients respectively (psi/ft).

Eaton's model [14] estimates;

$$
F P G=\left(\frac{v}{1-v}\right) \times\left(G_{O B}-G_{P P}\right)+G_{P P}
$$

A major challenge in the formula is determining the value $\left(\frac{v}{1-v}\right)$. Unlike Eaton who back calculated to get a constant value of the poisson ratio $(v)$ as 0.25 . Meanwhile, this modified Eaton's model combines the famous John Castagna mud rock line linearized equation [19] with the theoretical poisson ratio formula to estimate $\left(\frac{v}{1-v}\right)$. This was done because in the general case the value of $\left(\frac{v}{1-v}\right)$ varies unlike Eaton proposed.

From John Castagna mud rock line linearized equation;

$$
V_{p}=1.16 V_{s}+1360(\mathrm{~m} / \mathrm{s})
$$

Expressing this in terms of $\mathrm{V}_{\mathrm{s}}$ gives;

$$
V_{\mathrm{s}}=\left(\frac{V_{p-\mathbf{1 3 6 0}}}{1.16}\right) \mathrm{m} / \mathrm{s}
$$

Recall, that the theoretical poisson ratio ( $v$ ) formula is given by

$$
v=\frac{V_{p}^{2}-2 V_{s}^{2}}{2\left(V_{p}^{2}-V_{s}^{2}\right)}
$$

Shear waves can be propagated through solid only because they are rigid and not through gas or liquid, unlike compressional waves that can be propagated through the three states of matter i.e solid, liquid, and/or gas.

Hence considering this fact, shear waves slowness $\Delta \mathrm{t}_{\mathrm{s}}$ track which would produce shear wave velocity $\left(V_{s}\right)$ are rarely available on a log track, therefore this is circumvented (put off) by substituting the value of $V_{s}$ in equation ( $x i$ ) with that of equation $(x)$, doing this gives;

$$
v=\frac{V_{p}^{2}-2\left(\frac{V_{p}-1360}{1.16}\right)^{2}}{2 V_{p}^{2}-2\left(\frac{V_{p}-1360}{1.16}\right)^{2}}
$$

Substituting these variables into its appropriate places and doing mathematical simplification helps in generating the modified Eaton's model as;

$$
F P G=\left(\frac{0.486\left(V_{p}-7566\right) \times\left(747-V_{p}\right)}{V_{p}^{2}}\right)
$$

Where; $V_{p}=$ Primary wave velocity $(\mathrm{m} / \mathrm{s}), V_{s}=$ Secondary wave velocity $(\mathrm{m} / \mathrm{s})$, GoB \& GPp= overburden and pore pressure gradients respectively (psi/ft), $v=$ Poisson ratio (dimensionless), FPG= formation fracture pressure gradient (psi/ft).

Figure 2 shows the plots of the Eaton's FPG model and the formation fluid pressure gradient vs Depth. From Figure 2, the grey line at the left represent the Eaton's FPG model and the black line on the right represent the formation fluid pressure gradient respectively. Due to the Eaton's assumed Poisson ratio value of 0.25 , hence the seemingly consistency trend, hence there is no visible crossover between the Eaton's FPG and formation fluid pressure gradient, which is not suitable for the Niger Delta area because the Poisson ratio did not consider variations with depth. However it is not with certainty that the formation would fracture except the FPG is merged with formation pressure gradient of the well as can be seen in Figure 3. Figure 3 shows the logarithmic crossplots of pore pressure gradient (GPP) against the ratios of the normal shale resistivity to observed shale resistivity $\left(R_{n} / R_{0}\right)$ (i.e GppvsRn/Ro). 


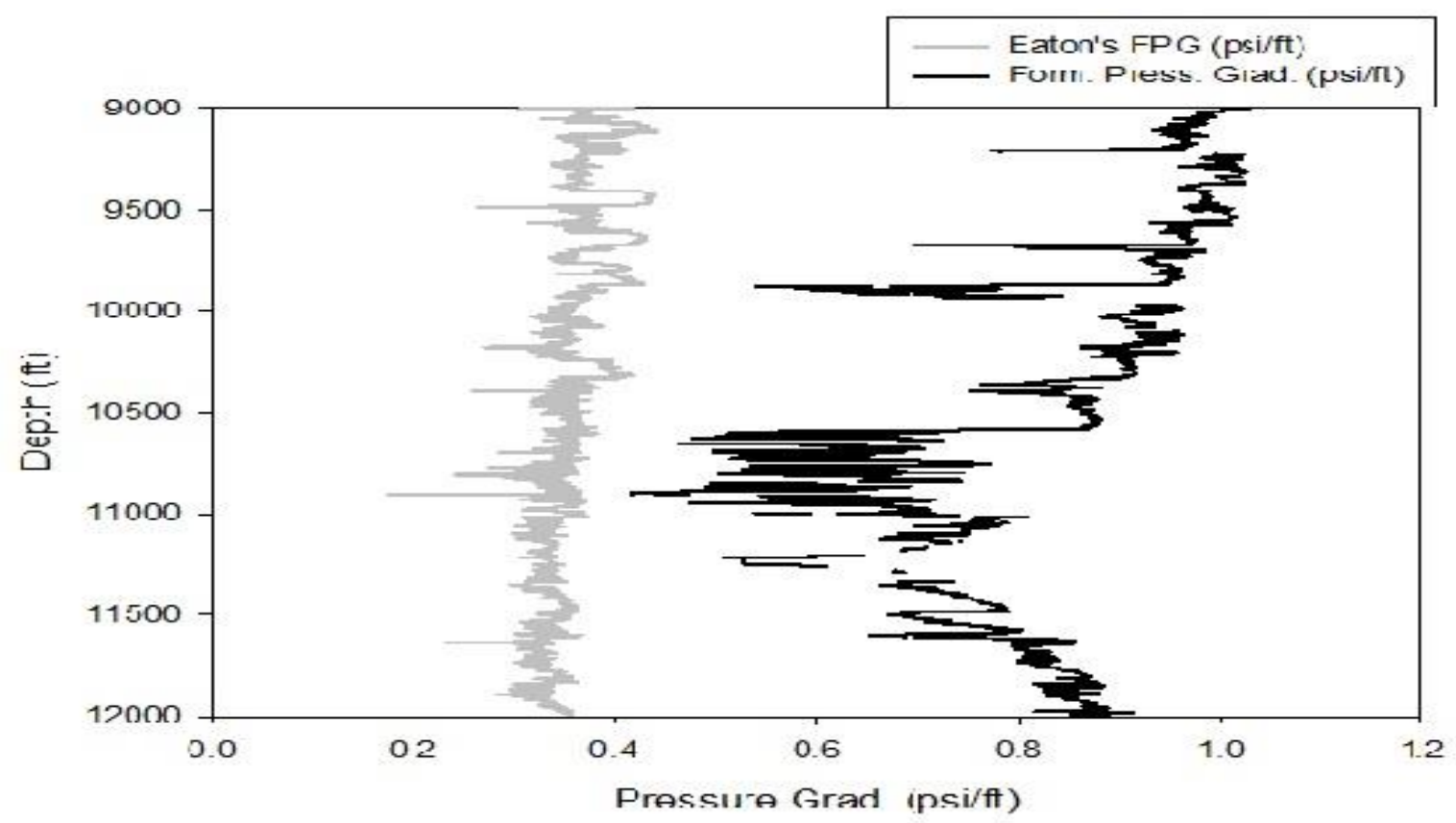

Figure 2: Plots of Eaton's FPG \& Formation fluid Press. Grad. vs Depth.

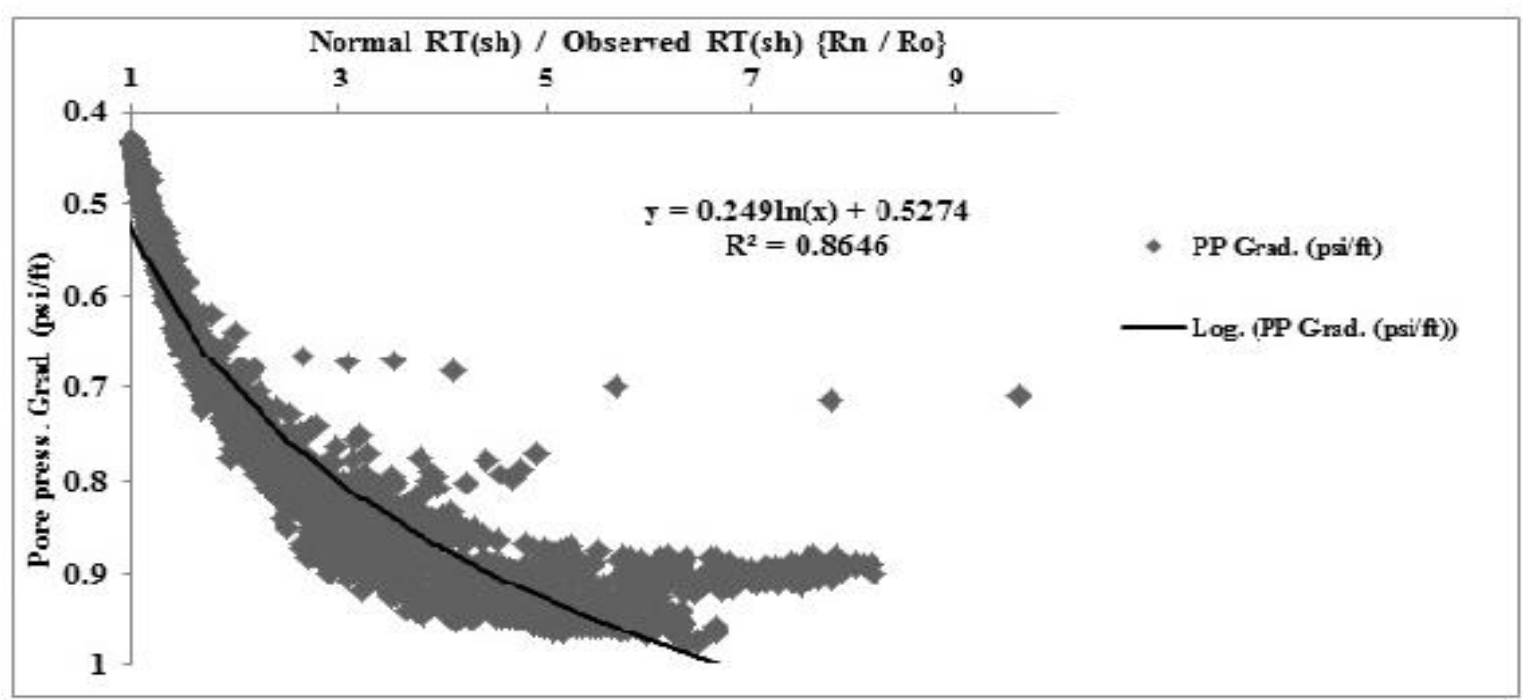

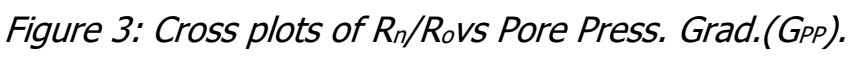

The formation fluid pressure gradient of the well is obtained once the pore pressure gradient Gpp is plotted against the ratios of the normal shale resistivity to observed shale resistivity (i.e GppvsRn/ $R_{0}$ ) as can be seen from the Figure 3 , the equation generated gives the formation fluid pressure gradient, once this is achieved, it is then merged with the crossplots of both the Eaton's FPG model and modified Eaton's FPG model respectively.

Figure 4 shows the cross plots of modified Eaton's FPG model \& Formation fluid Pressure Gradient vs Depth. From Figure 4, the grey line on the left represents the modified Eaton's Fracture Pressure Gradient (FPG) model, and the black line on the right represents the formation fluid pressure gradient of the well. This is suitable for the Niger Delta area because variation of Poisson ratio was considered with depths, unlike the Eaton's model who just considered a constant Poisson ratio of 0.25 .

Hence, predictable fracturable depths are deduced when there is a visible cross over between the formation pressure gradient and the modified Eaton's FPG model as depicted by the arrow, the Poisson ratio at such depth is determined. This serves as a guide when drilling through the narrow window margin in order not to fracture the formation which may lead to loss circulation and eventually well control situations. 


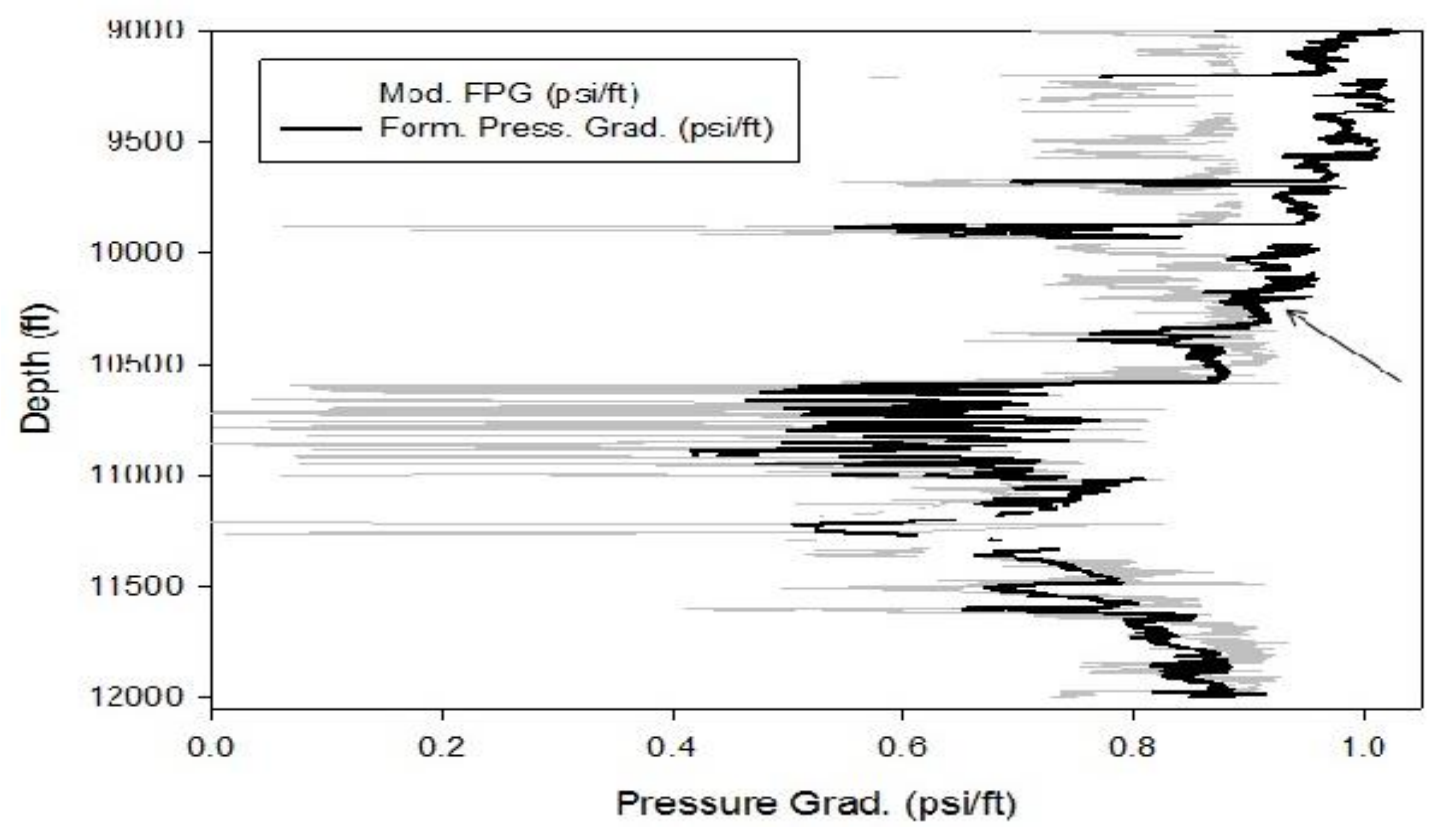

Figure 4: Cross plots of modified Eaton's FPG \& Form. Press.Grad.vs Depth.

\section{DISCUSSION OF RESULTS}

Although, there are many difficulties in predicting insitu pressures and formation fracture pressure gradient (FPG) measurement owing to the fact that these quantities are sensitive to mineralogy of the formation, petrophysical parameters, e.t.c.

From the data analysis of the 6 well logs obtained, their predictable fracturable depths were obtained alongside their Poisson ratio's as can be observed from the crossplots in Figure 3 for each well respectively. Hence this then guided generation of the ranges of Poisson ratio's for the Niger Delta region.

The sensitivity analysis was carried out on the model by varying each input parameters in order to determine which of the parameters will provide significant impact on the output for each well. The density input parameter was found to contribute significantly to the model. This parameter must therefore be considered for accurate prediction of FPG. Table 1 shows the data analysis summary together with its sensitivity analysis on the model.

Table 1: Data Analysis Summary with Sensitivity Analysis on the modified FPG model.

\begin{tabular}{|c|c|c|c|c|c|c|c|}
\hline \multirow{2}{*}{$\begin{array}{l}\text { Case } \\
\text { Study }\end{array}$} & \multirow{2}{*}{$\begin{array}{l}\text { Fracturable } \\
\text { Depths (Ft) }\end{array}$} & \multirow{2}{*}{$\begin{array}{c}\text { Poisson } \\
\text { Ratio }\end{array}$} & \multicolumn{5}{|c|}{ SENSITIVITY ANALYSIS ON FPG MODEL } \\
\hline & & & Depth (ft) & GR (API) & Density (g/cc) & RT (ohm.m) & DTC (us/ft) \\
\hline \multirow{3}{*}{ Well 1} & 7911.5 & 0.3572 & \multirow{3}{*}{$\begin{array}{c}\text { Directly } \\
\text { proportional but } \\
\text { minimal effect }\end{array}$} & \multirow{3}{*}{ No impact } & \multirow{3}{*}{\begin{tabular}{|c|} 
Directly \\
proportional with \\
great effect
\end{tabular}} & \multirow{3}{*}{$\begin{array}{l}\text { Varies, about } \\
1 / 40 \text { times }\end{array}$} & \multirow{3}{*}{$\begin{array}{c}\text { Varies, about } \\
\text { 1/33 times }\end{array}$} \\
\hline & 7959 & 0.3799 & & & & & \\
\hline & 8133 & 0.3841 & & & & & \\
\hline \multirow{3}{*}{ Well 2} & 7044 & 0.3866 & \multirow{3}{*}{$\begin{array}{c}\text { Directly } \\
\text { proportional but } \\
\text { minimal effect }\end{array}$} & \multirow{3}{*}{ No impact } & \multirow{3}{*}{$\begin{array}{c}\text { Directly } \\
\text { proportional with } \\
\text { great effect }\end{array}$} & \multirow{3}{*}{$\begin{array}{l}\text { Varies, about } \\
1 / 200 \text { times }\end{array}$} & \multirow{3}{*}{$\begin{array}{c}\text { Varies, about } \\
3 / 200 \text { times }\end{array}$} \\
\hline & 9191 & 0.3842 & & & & & \\
\hline & 10617.5 & 0.3592 & & & & & \\
\hline \multirow{3}{*}{ Well 3} & 6228 & 0.3587 & \multirow{3}{*}{$\begin{array}{c}\text { Directly } \\
\text { proportional but } \\
\text { minimal effect }\end{array}$} & \multirow{3}{*}{ No impact } & \multirow{3}{*}{$\begin{array}{c}\text { Directly } \\
\text { proportional with } \\
\text { great effect }\end{array}$} & \multirow{3}{*}{$\begin{array}{c}\text { Varies, about } \\
1 / 10 \text { times }\end{array}$} & \multirow{3}{*}{$\begin{array}{c}\text { Varies, about } \\
\text { 3/20 times }\end{array}$} \\
\hline & 8228.5 & 0.384 & & & & & \\
\hline & 9478.5 & 0.345 & & & & & \\
\hline \multirow{3}{*}{ Well 4} & 9150 & 0.3812 & \multirow{3}{*}{$\begin{array}{c}\text { Directly } \\
\text { proportional but } \\
\text { minimal effect }\end{array}$} & \multirow{3}{*}{ No impact } & \multirow{3}{*}{$\begin{array}{c}\text { Directly } \\
\text { proportional with } \\
\text { great effect }\end{array}$} & \multirow{3}{*}{$\begin{array}{l}\text { Varies, about } \\
1 / 200 \text { times }\end{array}$} & \multirow{3}{*}{$\begin{array}{c}\text { Varies, about } \\
1 / 100 \text { times }\end{array}$} \\
\hline & 9252 & 0.4039 & & & & & \\
\hline & 10585 & 0.3342 & & & & & \\
\hline \multirow{3}{*}{ Well 5} & 6719.5 & 0.3875 & \multirow{3}{*}{$\begin{array}{c}\text { Directly } \\
\text { proportional but } \\
\text { minimal effect }\end{array}$} & \multirow{3}{*}{ No impact } & \multirow{3}{*}{$\begin{array}{c}\text { Directly } \\
\text { proportional with } \\
\text { great effect }\end{array}$} & \multirow{3}{*}{$\begin{array}{l}\text { Varies, about } \\
1 / 200 \text { times }\end{array}$} & \multirow{3}{*}{$\begin{array}{c}\text { Varies, about } \\
1 / 100 \text { times }\end{array}$} \\
\hline & 7200 & 0.3738 & & & & & \\
\hline & 8131.5 & 0.3671 & & & & & \\
\hline \multirow{3}{*}{ Well 6} & 7687.5 & 0.3837 & & & Directly & & \\
\hline & 9225 & 0.349 & & No impact & proportional with & Varies, about & Varies, about \\
\hline & 10323.5 & 0.3836 & & & great effect & $1 / 200$ times & $1 / 200$ times \\
\hline
\end{tabular}

where; GR, RT, and DTC denotes Gamma Ray, True Resistivity and Compressional sonic well logs respectively. 


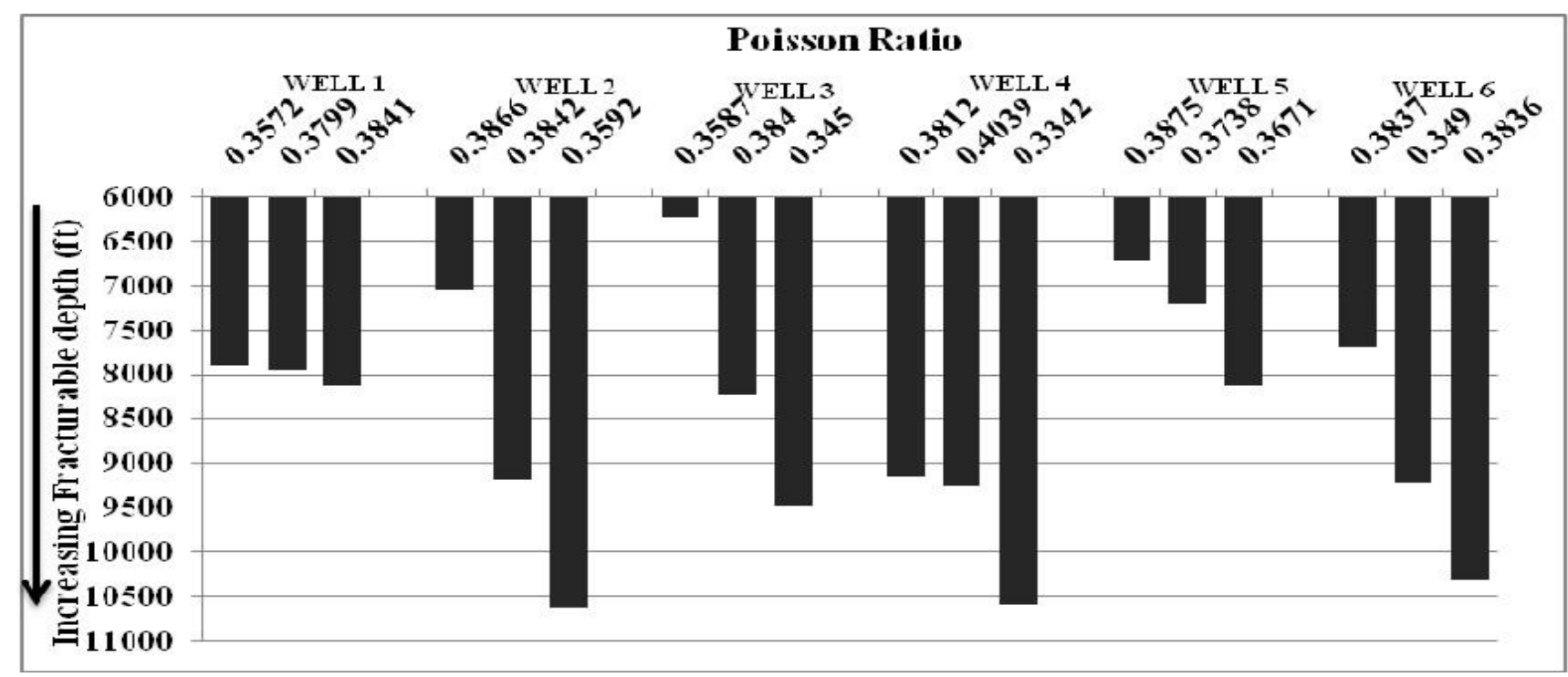

Figure 5: Chart showing Fracturable depths vs Poisson ratio for the 6 different wells as deduced from table 1.

From this chart, it was observed that on average the Poisson's ratio was at about 0.3724 , (this value was arrived at when the various poisson ratio values from each well were added and divided by 18 ) which helps supports the claim for the range of Poisson's ratio for the region which was estimated to be at about $0.35 \sim 0.40$.

\section{CONCLUSION(S)}

A modified Eaton's model has been developed to predict Fracture Pressure Gradient (FPG) at any depth the mud line for the Niger Delta environment, while a generalized range of Poisson's ratio was also predicted for the region.

It was established that the formations tend to fracture at depths of about $6700 \mathrm{ft}-10,000 \mathrm{ft}$ in the Niger Delta environment at Poisson's ratio of about 0.35-0.40, consequently, from the sensitivity analysis carried out, the fluid density played a significant role in the development of the modified model. However, changes in depth produces a direct but minimal effect on the results of the model, while the resistivity and DTC varies.

\section{REFERENCES}

[1] Aadnoy, B.S. and Reza, L.M. Petroleum Rock Mechanics: Drilling Operations and Well Designs, Gulf Professional Publishing, Langford Lane, Oxford, UK, First edition, 2011.

[2] Jamal, A. et alDrilling Engineering, Heriot Watt Institute of Petroleum Engineering, Heriot Watt University, Aberdeen, UK, 2005.
[3] Robert, F. M. and Stefan, Z. M."Fundamentals of Drilling Engineering", SPE Textbook Series, Vol. 12, 2011.

[4] Saeed, F.Formation Pressure, FamaiChemieSirang Co. Ltd, India, 2016.

[5] Corredor, F., Shaw, J. H., and Bilotti, F. "Structural Styles in the Deep water fold and Thrust Belts of the Niger Delta", American Association of Petroleum Geologist Bulletin, Vol. 89, 2005, pp. 753-780.

[6] Nwankwo, C. N., and Kalu, S. O. "Integrated Approach to Pore Pressure and Fracture Pressure Prediction using Well Logs: Case study of Onshore Niger Delta Sedimentary Basin", Open Journal of Geology, Vol. 6, 2016, pp.1279-1295.

[7] Kogbe, C. A. Geology of Nigeria, $2^{\text {nd }}$ edition, Rock view Ltd., Jos Nigeria, 1989.

[8] Odumodu, C. F.Geothermal Gradients and Burial History Modelling in Parts of the Eastern Niger Delta, Nigeria.University of Nigeria, Nsukka, Enugu, Nigeria, 2011.

[9] Evamy, D. D., Haremboure, P., Karmmerling, W. A., and Molloy, F. A. "Hydrocarbon Habitat of Tertiary Niger Delta", AAGP Bulletin, Vol. 6, Number 2, 1978, pp. 1-39.

[10] Doust, H., and Omatsola, E. "Niger Delta, in J.D. Edwards, and P.A. Santogrossieds., Divergent/passive margin basins", American Association of Petroleum Geologists Memoir, vol. 48,1990 , pp. $201-238$

[11] Hubbert, M. K. and Willis, D. G. "Mechanics of Hydraulic Fracturing", Transactions of Society of 
Petroleum Engineers of AIME, Vol. 2, Number 1, 1957, pp. 153-163.

[12] Matthews, W. R., and Kelly, J. "How to Predict Formation Pressure and Fracture Gradient", Oil and Gas Journal, 1967, pp. 92-106.

[13] Pennebaker, E. S."An Engineering Interpretation of Seismic Data", Presented at the 43rd Annual Fall Meeting of SPE-AIME, Houston, USA, 1968.

[14] Eaton, B. A. "Fracture Gradient Prediction and Its Application in Oilfield Operations". Journal of Petroleum Technology of SPE, 1969.

[15] Christman, S. A."Offshore Fracture Gradients", Journal of Petroleum Technology of SPE, 1973, pp. 910-914.
[16] Eaton, B. A."How to Use Drilling Petrophysical Data in Prospect Evaluation", World Oil Conference by SPE, August 19-21, 1995.

[17]Baker Hughes, Formation Pressure Evaluation Reference Guide, Baker Hughes INTEQ Training and Development, Houston, USA, 1996.

[18] Pilkington, P. E."Fracture Gradient Estimates in Tertiary Basins". Petroleum Engineering Journal, Vol. 2, Number 3, 1978.

[19] Castagna, J. P., Batzle, M. L., and Eastwood, R. L. "Relationships between Compressional Wave and Shear-Wave Velocities in Clastic Silicate Rocks".Geophysics Journal, Vol.50 Number 4, 1985, pp. 571-581. 